\title{
Pronomes adverbiais locativos em cartas do português: trajetória, ordenação e função
}

Pronominal adverbs of place in Portuguese letters: trajectory, ordering and function

\section{Mariangela Rios de Oliveira Universidade Federal Fluminense}

\section{Abstract}

Analysis of the ordination patterns and of the functionality of the adverbial locative pronouns there, here, on the Portuguese trajectory, taking into account texts that belong to the genre letter, based on the linguistics functionalism perspective. Identification of the grammar and discursive-pragmatic motivations when using these constituents, in terms of order, polysemy and grammaticalization.

Keywords

Pronominal adverbs of place; letters; Portuguese language; sintax.

\section{Resumo}

Análise dos padrões de ordenação e da funcionalidade dos pronomes adverbiais locativos aí, ali, aqui, cá e lá na trajetória do português, a partir de textos do gênero carta, com base na perspectiva do funcionalismo linguístico. Identificação de motivações gramaticais e pragmático-discursivas no uso desses constituintes, em termos de ordem, polissemia e gramaticalização.

\section{Palavras-chave}

Pronomes adverbiais locativos; cartas; língua portuguesa; sintaxe. 


\section{Introdução}

$\mathrm{N}$

osso ponto de partida é a constatação de que, no estágio atual da pesquisa na linha funcionalista, cada vez mais é necessária e bemvinda a articulação da dimensão gramatical e da discursiva para a interpretação dos fenômenos linguísticos na perspectiva histórica. Em alguns pontos da morfossintaxe do português, como no tratamento da descrição e da funcionalidade dos advérbios, por exemplo, a combinação das duas dimensões referidas pode contribuir para análises mais abrangentes, que levem em conta, para além dos padrões estruturais, outras motivações, relativas ao contexto pragmático-discursivo em que se articulam as interações sociais.

Com base nessas premissas, investigamos aqui, apoiando-nos em uma variável estrutural, a ordem em relação ao verbo, o comportamento semânticosintático dos pronomes adverbiais locativos aí, ali, aqui, cá e lá em textos portugueses do gênero epistolar, a partir de seus subgêneros, produzidos em sincronias que compreendem o período arcaico, os séculos XVIII e XIX, chegando ao português contemporâneo. ${ }^{1}$ Esses cinco itens foram selecionados em razão de sua maior frequência, diante dos demais da categoria, nos textos pesquisados.

Aanálise, fundamentada no funcionalismo linguístico, nos termos de Traugott e Dasher (2005), Brinton e Traugott (2006), Heine e Kuteva(2005) e Fischer, Norde e Perridon (2004), entre outros, alia a dimensão gramatical (investigação das trajetórias de polissemia e de gramaticalização) e a pragmático-discursiva (motivações relativas ao gênero e às sequências tipológicas em elaboração, ao perfil do remetente e do destinatário das cartas), conforme Berlinck, Barbosa e Marine (2008), Oliveira (2007) e Barbosa (2007)

Entendemos que a perspectiva de investigação histórica pode nos apontar tendências de mudança, de variabilidade e de continuidade no uso dos pronomes adverbiais locativos em análise. Tais tendências devem ser consideradas ainda como contribuição para o maior conhecimento das regularidades linguísticas que definem o gênero epistolar, como as sequências tipológicas (BONINI, 2005; MARCUSCHI, 2002) elaboradas prioritariamente nesse gênero. 
Nossa investigação parte das seguintes hipóteses, entre outras: a) a classe dos pronomes adverbiais locativos constitui uma categoria prototípica (TAYLOR, 1995), em que aqui e ali se situam no eixo central e aí e lá ocupam posições marginais; b) pronomes adverbiais locativos prototípicos articulam referência física e concreta, escopando o constituinte verbal e ordenando-se imediatamente após esse elemento; c) a posição contígua à direita do verbo é tendência mais recente no português e sua fixação começa a se evidenciar no século XIX; d) trajetórias de polissemia (espaço > tempo > texto) e de gramaticalização (advérbio > conector; advérbio > clítico), principalmente no uso de aí e lá, são tendências também mais recentes na língua, incrementadas a partir do século XIX; e) fatores pragmático-discursivos, como o gênero e as sequências tipológicas em elaboração, o perfil dos interlocutores, o nível de habilidade do remetente e as condições de produção textual, motivam a seleção e a frequência de uso dos pronomes adverbiais locativos.

Com base nas hipóteses apresentadas, objetivamos, neste artigo, proceder ao levantamento e à análise interpretativa dos pronomes aí, ali, aqui, cá e lá em três etapas da trajetória do português, identificando tendências de variabilidade, de continuidade e de mudança no uso desses constituintes. Pretendemos também aliar a abordagem gramatical à discursiva, na consideração do vínculo entre essas duas dimensões na seleção, organização e frequência no uso dos referidos pronomes.

$\mathrm{O}$ artigo divide-se em quatro seções. Na primeira, trazemos os fundamentos teóricos que orientam nossa perspectiva analítica, com destaque para os pressupostos usados na pesquisa dos pronomes adverbiais locativos. Na segunda, apresentamos os corpora que serviram de base empírica, com sua caracterização em termos do gênero discursivo epistolar e a justificativa para a seleção das três fases da língua trabalhadas. Na terceira, procedemos à análise dos dados, com foco em aspectos quantitativos e qualitativos, na vinculação desses usos ao gênero e às sequências tipológica articuladas. Por fim, na quarta seção, discutimos os resultados da pesquisa em termos de tendências de uso, bem como destacamos a relação entre tais usos e o contexto pragmático-discursivo que os motiva.

\section{Pressupostos teóricos}

De acordo com perspectiva funcional que nos orienta, nos termos de Traugott e Dasher (2005) e Heine e Kuteva (2005), entre outros, os usos linguísticos são forjados e estabilizados, como expressões regulares e gramaticais, 
nas práticas interacionais. Dessa forma, há relação estreita entre forma e função, no sentido de que aquela é resultante desta, de que os padrões estruturais em uso são produto das interações comunicativas, em que fatores pragmáticodiscursivos, aliados a aspectos cognitivos e socioculturais, entre outros, concorrem para a regularidade linguística.

Nessa perspectiva, ganha destaque a chamada teoria localista (BATORÉO, 2000), segundo a qual os sentidos têm uma base mais concreta, relativa à dimensão espacial, e daí, por metáfora, derivam para a referência temporal e, a seguir, para a textual. Trata-se da proposta da perspectivação espacial usada para a perspectivação de outras dimensões, como a temporal e a discursiva. Em relação a nossos objetos de pesquisa, esse cline semântico pode ser observado, respectivamente, em fragmentos do português, como nos três exemplos: aí na esquina, aí por volta das duas da tarde e chegou, aí começou a trabalhar.

Em termos semânticos, destacamos também, como pressuposto para análise, a granulidade, conforme se apresenta em Batoréo (2000). Trata-se de um termo tomado à Inteligência Artificial, que define as diferenças nas regiõesde-vizinhança dos conjuntos, estabelecendo dois subsistemas - granulidade vasta e granulidade fina ou estreita. A granulidade vasta diz respeito à imprecisão espacial, à falta de pontualidade ou determinação de um elemento no espaço; já a granulidade fina relaciona-se à precisão, que chega inclusive a tender para a referência um ponto preciso no espaço. Assim, no eixo da granulidade vasta, em termos de nossos objetos de estudos, encontram-se os pronomes cá e lá, uma vez que sua referência é genérica e imprecisa; trata-se de espaços usados na indeterminação ou indefinição, como verificamos em expressões como vem cá, lá fora ou ainda sei lá, em que, neste terceiro caso, a imprecisão é redimensionada, possibilitando a referência negativa. Por outro lado, a tríade aqui, aí e ali corresponde à granulidade fina, já que sua referência aponta para um espaço definido e preciso, geralmente conhecido pelos interlocutores, ilustrado em articulações como: vem aqui, aí fora, ali na porta.

Com relação à metonímia, instância destacada na mais recente tendência dos estudos funcionalista, de acordo com Traugott e Dasher (2005), consideramos alguns aspectos construcionais envolvidos no uso dos pronomes locativos. Tal consideração vai ao encontro da concepção de que metaforização e metonimização não são excludentes, mas sim processos que se implicam, no sentido de que a metáfora é tomada como resultado ou efeito da metonímia. Um desses aspectos mais 
relevantes em termos do redimensionamento dos fatores estruturais na abordagem funcionalista é o conceito de unidade pré-fabricada (UPF), elaborado por Erman e Warren (2000). Segundo tal conceito, determinadas sequências de palavras são convencionalizadas e, uma vez assim configuradas e consensuadas na comunidade linguística, passam a constituir um todo de sentido e forma, um construto de ordem superior que articula determinada referência, distinta da mera soma de seus constituintes. Outra característica da UPF é seu alto nível de fixação, que faz com que, em muitos casos, seja inviável a inserção de demais elementos entre seus constituintes ou a mudança posicional dos mesmos no interior da unidade. Tratando a UPF como processo gradiente, os autores propõem quatro tipos ou grupos, um lexical e três funcionais (gramatical, pragmático e reduzível). As UPFs lexicais denotam entidades, propriedades ou eventos/situações de diversos tipos; as gramaticais articulam referência intralinguística e participam da estruturação sintática do texto; as pragmáticas, mais recorrentes na modalidade falada e registros menos formais, concorrem para o monitoramento interacional e não integram a estrutura sintática; as reduzíveis são resquícios de construtos altamente integrados, fruto da junção de constituintes que não partilham o mesmo status gramatical, como as formações do inglês don't, I'm ou it's. Podemos ilustrar a taxonomia referida pelos autores, em termos dos três primeiros grupos, com nossos objetos de pesquisa, assim, expressões como lá fora ou aqui dentro encontrar-se-iam no grupo das UPFs lexicais, uma vez que fazem referência a um espaço geograficamente referido; entre as UPFs funcionais, teríamos a expressão aí está ou daqui vem no grupo das gramaticais, enquanto sei lá ou vá lá estariam situadas entre as pragmáticas. No tocante às reduzíveis, devido a seu alto nível de integração e metaforização, optamos por não estabelecer paralelo com os pronomes locativos do português.

A proposta das UPFs tem estreita correlação com a abordagem construcional proposta por Goldberg (1995; 2006). Conforme a referida autora, a unidade básica ou central do uso linguístico é a construção, entendida como um tipo de pareamento função-forma. Assim, o conhecimento e a competência comunicativa estão intimamente associados ao manejo eficiente das construções de uma dada língua. A concepção de unidade maior de sentido e de expressão bem como a indissociabilidade de seus constituintes caracterizam as UPFs e fazem delas exemplares de construções.

Outro pressuposto que podemos relacionar ao conceito de UPF é o de inferência sugerida (TRAUGOTT; DASHER, 2005, p. 17), segundo o qual, nas 
interações cotidianas, os interlocutores chegam a sentidos derivados de combinações semântico-sintáticas oriundas do contexto de produção. Para tanto, os emissores valem-se de constituintes disponíveis na língua e os reorganizam, no intuito de tais termos expressarem sentidos mais comunicativos, como crenças, valores, atitudes, entre outros; trata-se do processo de subjetificação. As chamadas UPFs gramaticais e pragmáticas, por exemplo, pelo tipo de função que cumprem, seriam consequentes, via sistematização, de arranjos estratégicos feitos pelos emissores (subjetificação) e da negociação comunicativas com os receptores (intersubjetificação).

Por levar em conta a estreita vinculação entre gramática e discurso, trabalhamos também com a concepção de gêneros textuais, conforme Marcuschi (2002, p. 19), que define essa instância comofenômenos históricos, profundamente vinculados à vida cultural e social. $\mathrm{O}$ autor destaca ainda o viés coletivo $\mathrm{e}$ comunicativo dos gêneros, enfatizando a maleabilidade, a dinamicidade e a plasticidade de que se revestem. Nesse sentido, as cartas que analisamos são consideradas um gênero textual e, do ponto de vista linguístico, são construídas por intermédio da seleção e da organização de sequências tipológicas (MARCUSCHI, 2002, p. 25; BONINI, 2005). Tais sequências representam construtos de enunciados caracterizados por marcas específicas em termos lexicais, morfossintáticos, entre outros, e se classificam em narração, argumentação/dissertação, descrição, injunção e exposição. Assim, um texto pode ser tratado, em nível maior, em termos do gênero a que corresponde, e, em nível menor, em termos das sequências de enunciados de que é constituído. Tal tratamento é possibilitado pela motivação entre gênero textual e sequências tipológicas. As cartas que nos servem de base empírica, portanto, ensejam a seleção e a organização dos enunciados que as constituem, e os pronomes locativos pesquisados concorrem para configuração semântico-sintática das sequências tipológicas forjadas nesse ambiente textual.

\section{Corpora em análise}

Os textos que nos serviram de fonte de pesquisa pertencem ao gênero discursivo epistolar. Caracterizam-se pela elaboração escrita, pela presença, pelo menos, de um remetente e de um destinatário; trata-se de produções situadas, de modo explícito ou não, num espaço e num tempo determinados, servindo a 
propósitos comunicativos que se encontram comprometidos com as marcas sócio-históricas do período de sua elaboração.

De acordo com Berlinck, Barbosa e Marine (2008, p. 174), consideramos o gênero epistolar como o ambiente discursivo em que se encontram/conflitam as várias estratégias do autor/narrador e do receptor/leitor, constituindo-se uma fonte promissora para a pesquisa da variação/mudança linguística. $\mathrm{O}$ referido gênero engloba muitos subgêneros, dependendo do propósito discursivo em elaboração. Assim, elegemos as cartas como o texto básico do qual partem nossas análises dos advérbios pronominais locativos, em três grupos distintos: carta oficial ou pública, cartas pessoais e cartas de leitores.

Quanto às sincronias trabalhadas, concentramo-nos em três períodos da língua, com base em Mattos e Silva (1991): o arcaico, o moderno, relativo aos séculos XVIII e XIX, e ainda o português contemporâneo, a partir de textos do final do século XX. Esse recorte levou em conta alguns fatores, entre os quais destacamos: a) o objetivo de dar conta de três períodos mais ou menos distintos e representativos da história da língua portuguesa, desde sua fase mais inicial até a atual; b) a identificação do século XIX como o momento decisivo rumo à estabilização de usos representativos de uma "gramática brasileira" (BERLINCK; BARBOSA; MARINE, 2008; TARALLO, 1990); c) a intenção de capturar tendências de continuidade, de variabilidade e de mudança na trajetória da língua com base nos três períodos selecionados.

Ainda com relação à seleção dos corpora, faz-se necessário um esclarecimento acerca da escolha de cartas representativas de duas normas do português - a de Portugal e a do Brasil. Para o levantamento de dados em fontes correspondentes à fase mais antiga da língua, constituída pelo período arcaico, bem como para uma amostragem do início do português moderno, ou seja, o século XVIII e parte do XIX, utilizamos cartas portuguesas; para a pesquisa de parte do século XIX e do português contemporâneo, debruçamo-nos sobre cartas brasileiras. Essa decisão metodológica deveu-se às condições histórico-culturais do português do Brasil, que, conforme assinalado no parágrafo anterior, somente se constitui como norma distinta e se estabiliza como variante em relação aos usos europeus já no século XIX. Até esse período, a intelectualidade brasileira e a produção local, salvo algumas exceções, tinham forte influência dos usos praticados em Portugal, razão pela qual, até o século XVIII, a consideração desse fator diatópico não nos pareceu relevante. Assim, a distribuição dos corpora de pesquisa, de algum modo, orienta-se por essa trajetória da língua: fontes 
portuguesas para o período arcaico, o século XVIII e parte do XIX; fontes brasileiras para parte do século XIX e para a fase contemporânea.

Do período arcaico, investigamos a "Carta de Caminha". ${ }^{2}$ Elaborada pelo escrivão da frota de Cabral em 1500, este documento, considerado o primeiro testemunho oficial e público da terra brasileira, conta com detalhe e minúcia, numa profusão de sequências de tipologia narrativa e descritiva, as características do local descoberto, com sua população, flora, fauna, marcas topográficas, entre outras, e os acontecimentos envolvidos no contato inicial entre índios e portugueses. Como se trata de texto dirigido oficialmente ao rei D. Manuel, em tom cerimonioso e com maior controle de sua produção, elaborada por remetente hábil, consideramos esse texto, nos termos de Barbosa (2007), como representativo da norma culta da época de sua produção.

Dos séculos XVIII e XIX, que constituem a fase de transição para os usos contemporâneos, trabalhamos com cartas pessoais disponibilizadas em sites da UFRJ e USP. ${ }^{3}$ Trata-se de um subgênero epistolar que se caracteriza pela comunicação em âmbito privado e texto não muito extenso, no qual remetente e destinatário partilham uma série de experiências e se comunicam com base em pressupostos, conferindo a esse tipo de correspondência a marca da intimidade. Dependendo do perfil dos envolvidos na interação e dos fatores pragmáticos que a marcam, as estratégias linguísticas em uso, entre as quais se situa a articulação dos pronomes adverbiais locativos pesquisados, podem apresentar distinções.

Nesses dois séculos, incluímos o locativo cá no levantamento dos dados, devido à alta frequência em que foi encontrado nos textos pesquisados.

Levantamos exaustivamente nossos objetos de análise em 35 cartas pessoais da Marquesa de Alorna, escritas no século XVIII. D. Leonor de Almeida, a Marquesa de Alorna, uma mulher letrada em relação às demais de sua época, produziu esses textos, carregados de emoção e de dramaticidade, para seu pai, um preso político considerado inimigo do rei de Portugal, D.José. A Marquesa, a irmã e a mãe estavam exiladas num convento em Chelas e seu pai enviavalhes com dificuldade cartas escritas com o próprio sangue, as quais a jovem Leonor começou a responder, desde que completou onze anos de idade, em consequência da enfermidade da mãe. A Marquesa somente saiu da prisão no convento aos dezoito anos, quando o rei lusitano faleceu.

Do século XIX, levantamos os dados em 82 cartas, distribuídas equilibradamente em dois grupos. O primeiro conjunto de cartas pertence à família Ottoni. Nessa correspondência, dois avós escrevem na segunda metade do século, do 
Rio de Janeiro, a seus dois netos, na França; trata-se de um típico casal da classe média de então, em que o homem exercia várias e prestigiadas atividades profissionais, chegando, inclusive, ao cargo de senador da República, enquanto a mulher dedicava-se basicamente às atividades domésticas, com pouco nível de letramento. O segundo grupo de cartas diz respeito à correspondência de Eça de Queiros a Oliveira Martins. Nessas 41 produções, o poeta português dirige-se ao amigo, num estilo cuidadoso, demonstrando sua habilidade com os recursos linguísticos.

Em relação ao português contemporâneo, trabalhamos com dois grupos de cartas distintos. O primeiro, mais próximo às fontes dos séculos XVIII e XIX, é composto também por cartas pessoais de Mário de Andrade dirigidas a Murilo Miranda. O segundo grupo configura-se no conjunto de 101 trechos de cartas de leitores publicadas nos jornais $O$ Globo, Jornal do Brasil, Folha de São Paulo e nas revistas IstoÉ, Veja, Época e IstoÉ Gente, no período de dezembro de 2003 a maio de 2004. De acordo com Fontanini (2002), as cartas de leitores ficam a meio caminho entre os domínios público e privado, portanto, de acordo com os demais corpora aqui referidos, esses textos se situam entre a Carta de Caminha, da fase arcaica (domínio público), e as cartas pessoais, dos séculos XVIII e XIX (domínio privado). Conforme a mesma autora, as cartas de leitores constituem textos marcados por características ideológicas dos remetentes, tais como: crenças, conceitos, valores, propósitos discursivos, entre outras, bem como por aspectos que dizem respeito aos fatores sociais que os influenciaram, de alguma maneira, ao elaborar o texto. Os leitores, como remetentes, dirigem-se a um fórum público (a revista ou o jornal), manifestando-se em relação a um acontecimento ou matéria publicada. $\mathrm{O}$ tom opinativo e persuasivo costuma marcar esse subgênero discursivo.

\section{Ordem e função na trajetória do português}

Nesta seção, apresentamos, com base nas sincronias pesquisadas, a ordenação e a funcionalidade dos pronomes adverbiais locativos em análise. $\mathrm{Na}$ interpretação dos dados, procuramos estabelecer relação entre esses usos (no nível gramatical) e os fatores pragmático-discursivos que poderiam condicioná-los (no nível do texto).

Sabemos que, como integrantes de categoria híbrida, marcada por grande maleabilidade funcional, nossos objetos de pesquisa podem escopar o verbo, em 
seu uso prototípico, ou podem ainda incidir sobre outros constituintes, em formações mais específicas e marcadas. Como Oliveira e Aguiar (2009), Tavares (no prelo) e Braga e Paiva (2003), há contextos em que os pronomes estudados, notadamente aí, atuam pospostos a um sintagma nominal, em função nomeada de clítica ou especificadora, como em arranjos do tipo um menino aí e uma pessoa aí. Há também UPFs de natureza mais idiomática, expressões formulaicas, destituídas de elemento verbal ou mesmo nominal, que são integradas por pronomes locativos, como de lá para cá ou eis aqui. Desse variado espectro de contextos de uso, elegemos um específico e mais frequente, concernente à prototípica função adverbial, identificado como aquele em que $o$ pronome surge em ambiente oracional, relacionado, direta ou indiretamente, a um constituinte verbal. Assim, as ordenações de que tratamos aqui têm como eixo o verbo, na observação da maior ou da menor proximidade dos pronomes pesquisados em relação a esse constituinte central e também em termos de sua ordenação antes ou depois dele.

As cinco posições levantadas são: três pré-verbais - P1 (sujeito+ advérbio+verbo); P2 (advérbio+verbo), P3 (advérbio+inserção+verbo); duas pós-verbais - P4 (verbo+advérbio); P5 (verbo+inserção+advérbio). As tabelas das subseções seguintes são organizadas em torno desses cinco padrões de ocorrência.

\subsection{Século XV}

A Carta de Caminha, nosso representante do período arcaico da língua portuguesa, tem a seguinte distribuição dos locativos pelas cinco ordenações referidas:

TABELA 1

Ordenação de locativos na Carta de Caminha

\begin{tabular}{l|ccc|ccc}
\hline & \multicolumn{3}{|c|}{ Posições pré- verbais } & \multicolumn{3}{c}{ Posições pós- verbais } \\
\hline Locativo & P1 & P2 & P3 & P4 & P5 & Total \\
\hline Lá & - & 5 & - & 14 & - & 19 \\
Ali(y) & - & 26 & 6 & 12 & 1 & 45 \\
Aí(Hy) & - & 7 & - & 9 & 1 & 17 \\
Aqui(y) & - & 9 & 5 & 12 & 2 & 28 \\
Total & - & 47 & 11 & 47 & 4 & 109 \\
\hline
\end{tabular}


Como se pode observar, os 109 registros distribuem-se equilibradamente entre posições pré-verbais (58 dados) e pós-verbais (51), demonstrando a variabilidade posicional dos termos em análise nessa sincronia da língua. Desses 109 dados, 45 referem-se ao locativo aly, em sequências como:

(1) ... e despois moueo ocapitam peracjma ao longo do rrio que anda senpre acaram da praya e aly esperou huu velho que trazia na maão hua paa dalmadia. (p. 30)

Dos 45 registros de aly, a grande maioria, totalizando 32 dados, ordena-se antes do verbo, numa referência anafórica de sentido físico concreto, como se verifica em (1).

A seguir, cm 28 ocorrências, registra-se o uso de aquy:

(2) ... da marinha jem e simgraduras do caminho nõ darey aquy cõta a vossa alteza por queo nom saberey fazer... (p. 6)

Em (2), o advérbio aquy insere-se entre o verbo (darey) e seu argumento (cõta), num tipo de ordenação pouco recorrente no português contemporâneo. Nesse trecho, o locativo assume sentido físico virtual, referindo-se ao espaço da própria carta.

Nesse texto, os constituintes lá e hy funcionam regularmente com sentido mais concreto, em anáforas relativas a um espaço físico, como a seguir:

(3) ... mandou ocapitã aaquele degradado $a^{\circ}$ Ribeiro que se fosse out ${ }^{a}$ vez com eles. Oqual se foy e andou la huu boõ pedaço... (p. 34)

O pronome $h y$, nessa sincronia, tende ainda a se ordenar após o verbo, revelando seu uso preponderantemente adverbial. De suas 17 ocorrências, 10 são do tipo pós-verbal:

(4) ... mujtos deles os hiam logo poer e trra e outros os nõ punham. Amdaua hy huи que falaua mujto aos outros que se afastasem... (p. 24)

Em termos textuais, mais do que a informação da descoberta, percebe-se no texto de Caminha a preocupação com a minúcia e o detalhe, que se revela nos inúmeros relatos e descrições de que se compõe essa carta. Dos corpora pesquisados, foi nesta fonte que encontramos a maior frequência do uso de aly. Consideramos esse resultado, distinto das demais obras, motivado por fatores 
pragmático-discursivos muito específicos da Carta, em que preponderam os trechos de base tipológica narrativa (BONINI, 2005; MARCUSCHI, 2002). Na tabela seguinte, apresenta-se a distribuição dos dados pelas duas sequências em elaboração:

TABELA 2

Sequência tipológica dos locativos na Carta de Caminha

\begin{tabular}{l|c|c|c}
\hline Locativo & Descrição & Narração & Total \\
\hline Lá & 3 & 16 & 19 \\
Ali(y) & 5 & 40 & 45 \\
Aí(Hy) & 4 & 13 & 17 \\
Aqui(y) & 8 & 20 & 28 \\
Total & 20 & 89 & 109 \\
\hline
\end{tabular}

Além da preponderância da descrição e, mais ainda, da narração, como a correspondência se destina ao rei de Portugal, observa-se a constante preocupação do remetente em se mostrar humilde e, muitas vezes, declarar-se mesmo incapaz de transmitir com precisão tudo o que desejaria. Por outro lado, o escriba de 50 anos é hábil e competente (BARBOSA, 2007), cumprindo sua missão de escrever ao rei com elegância e estilo, de acordo com os padrões eruditos da época.

\subsection{Século XVIII}

Nas 35 cartas da Marquesa de Alorna a seu pai, temos o seguinte quadro de ordenação dos locativos:

TABELA 3

Ordenação de locativos nas cartas da Marquesa de Alorna

\begin{tabular}{l|ccc|ccc}
\hline & \multicolumn{3}{|c|}{ Posições pré- verbais } & \multicolumn{3}{c}{ Posições pós- verbais } \\
\hline Locativo & P1 & P2 & P3 & P4 & P5 & Total \\
\hline Lá & - & 6 & - & 8 & 2 & 16 \\
Ali & - & 6 & - & 2 & - & 8 \\
Aí & - & - & - & 1 & 1 & 2 \\
Aqui & - & 7 & 13 & 6 & 2 & 28 \\
Cá & - & 1 & 1 & 2 & 2 & 6 \\
Total & - & 20 & 14 & 19 & 7 & 60 \\
\hline
\end{tabular}


Em termos gerais, podemos dizer que os dados do século XVIII ainda revelam uso equilibrado entre posições pré e pós-verbais dos pronomes adverbiais locativos - dos 60 registros, 34 dados ordenam-se antes do verbo e 26 após o verbo. Tal como Caminha, a Marquesa de Alorna é uma remetente culta, uma mulher muito letrada para os padrões do perfil feminino de sua época.

No entanto, apenas a questão do letramento aproxima os dois remetentes. A Marquesa, além de sua condição feminina, é bem mais jovem e se encontra presa. Nessa situação, escreve ao pai textos marcados pela saudade, em depoimentos muito pessoais. Suas cartas, ao contrário da escrita por Caminha, não visam ao relato específico, não objetivam contar efetivamente nada; trata-se de declarações pontuadas pela emoção de uma família que se encontra perseguida e desmembrada. Em razão dessa característica, predominam nas cartas da Marquesa de Alorna as sequências tipológicas expositivas, injuntivas e descritivas, razão pela qual preponderam os usos de aquy, em 28 das 60 ocorrências totais, relativos ao espaço da remetente, e lá, em 16 dados, referentes ao espaço do destinatário ou de um terceiro referente. Devido a tal característica, 42 dos 60 dados dessas cartas classificam-se como usos exofóricos, tais como:

(5) Eis aqui me tem V.A. R. embargada pelas circunstâncias e sem poder adiantar nada, enquanto dura a moléstia do Marquês. (Carta 30)

(6) E assim como há mais de um ano tive o valor de profetizar todos êstes perigos, como V. A. R. pode recordar-se, pelas cartas que lá tem minhas. (Carta 35)

Em (5), ilustramos uma construção muito recorrente nas cartas da Marquesa, a unidade pré-fabricada (UPF), nos termos de Erman e Warren (2000), eis aqui. Trata-se de um sintagma por intermédio do qual a remetente expõe sua condição emocional e tece comentários acerca de sua situação. É justamente essa estratégia discursiva recorrente, motivada também pela referência ao um contexto espacial mais próximo à remetente, que favorece o maior número de ocorrências do locativo aqui nessas cartas.

Tal como observado no texto da fase arcaica, as cartas do século XVIII ainda não registram usos mais gramaticalizados de aí (hy). Os dois únicos registros desse pronome nas 35 cartas da Marquesa de Alorna se articulam em posição pós-verbal, na referência anafórica a espaço físico virtual, como (7): 
(7) Eu, que fàcilmente me deixo transportar a tôdas as situações possiveis, ainda às mais aflitivas, dou tanto preço à conservação de V. Ex.as! Acho aí tôda a minha glória, tôda a minha felicidade, ... (Carta 20)

Embora a referenciação seja anafórica e de sentido mais abstrato ou polissêmico, consideramos, efetivamente, que o locativo aí funciona em (7) como um típico membro da classe adverbial.

\subsection{Século XIX}

Neste século, já se prenuncia a tendência mais recente da ordenação pósverbal dos locativos prototípicos. Nas cartas pessoais do século XIX pesquisadas, os dois grupos estudados apresentam resultados um tanto distintos, um com mais equilíbrio de distribuição das ordenações e outro com evidente prevalência das posições pós-verbais. Nessa sincronia, é possível a verificação de tendências que se tornam mais evidentes no século XX.

Na tabela a seguir, encontram-se os dados coletados da correspondência dos avós Ottoni:

TABELA 4

Ordenação de locativos nas cartas da família Ottoni

\begin{tabular}{l|ccc|ccc}
\hline & \multicolumn{3}{|c|}{ Posições pré- verbais } & \multicolumn{3}{c}{ Posições pós- verbais } \\
\hline Locativo & P1 & P2 & P3 & P4 & P5 & Total \\
\hline Lá & - & 7 & 1 & 3 & 4 & 15 \\
Ali & - & - & 1 & - & - & 1 \\
Aí & 1 & 4 & - & 4 & 3 & 12 \\
Aqui & 4 & 10 & 7 & 8 & 8 & 37 \\
Cá & - & 1 & 2 & 3 & 5 & 11 \\
Total & 5 & 22 & 11 & 18 & 20 & 76 \\
\hline
\end{tabular}

ATabela 4 nos mostra que os 76 dados totais distribuem-se equilibradamente em 38 registros pré e 38 pós-verbais. Em termos absolutos, a posição P2 prepondera sobre as demais e o locativo aqui é o mais frequente, com 37 dos 76 registros gerais.

Tal como na carta da Marquesa, a família Ottoni, no papel de remetente, faz uso mais frequente do locativo que se refere a espaço próximo da primeira 
pessoa e de granulidade fina (BATORÉO, 2000) - aqui. Em suas 41 cartas, os avós Ottoni tecem uma série de comentários atinentes ao espaço em que se encontram:

(8) Aqui a novidade que houve é que cahio o ministerio do Joã̃ Alfredo e levaraõ 15 dias para organizarem outro depois de muitas historias subiraõ os liberaes. (Carta 38)

(9) A Maria Jozefina esteve aqui nanossa festa, e fes um comprimento a Vôvô. (Carta 33)

(10) ... daqui a um anno, quando o nosso netinho Misael tiver a mesma idade que tem hoje seu irmã̃, tambem elle ha de escrever assim. (Carta 3)

Esse espaço, conforme os três fragmentos ilustram, pode se referir exoforicamente ao Brasil, como um ambiente físico concreto (8); cataforicamente, pode ter sentido físico virtual (nossa festa), como em (9); e ainda assumir valor temporal, na articulação da construção daqui a um ano, como demonstra (10).

Ao se referirem ao espaço em que se situam seus destinatários - os netos -, os remetentes utilizam-se do locativo aí:

(11) Faço idéa da falta que ha de fazer ahi Ermelinda e Lulú; principalmente elle, tã̃ alegre, tã̃ disposto sempre a brincar. (Carta 15)

(12) O que vocês me disem do frio e neve ahi contrasta com os suadores que ca tomamos: em Outubro o thermotro chegou a $32^{\circ}$. (Carta 20)

Em relação ao fragmento (12), a distância entre o locativo e o verbo anteposto (posição P5) faz com que se possa, por reanálise, considerar que ahi escope o SN frio e neve, atuando como clítico ou especificador deste SN (Braga e Paiva, 2003). Contextos como (12) são considerados favorecedores de usos mais polissêmicos e categorialmente marginais de ahi.

Com relação ao pronome lá, talvez motivado por sua granulidade vasta (BATORÉO, 2000, p. 439), é utilizado pelos avós Ottoni na referência a comentários sobre terceiros, para informações aos netos acerca de situações e pessoas conhecidas do Brasil: 
(13) Nos ultimos dias deste mes ou primeiros de Fevereiro partirei para o Paraná para assistir a inauguraçã̃ da estrada de ferro, e de la me daõ a esperança de vir comigo Zulmira e seus dous filhinhos. (Carta 10)

Também a vasta granulidade pode ser apontada como um dos fatores para o uso do locativo cá em referências mais amplas e vagas, conferindo ao texto a marca da generalização, tal como:

(14) O que vocês me disem do frio e neve ahi contrasta com os suadores que ca tomamos. (Carta 20)

(15) Fiquei muito contente quando sua Mae medisse que em principio deMaio estarã̃ cá, pois estou com muitas saudades de voces todos. (Carta 28)

No português contemporâneo do Brasil, o locativo cá em (14) e (15) teria como uso correspondente e preferencial aqui. Em (14), inclusive, a menção ao locativo ahi motivaria a articulação contrastiva com aqui. Consideramos, portanto, os dois fragmentos anteriormente apresentados como padrões de expressão em desuso na sincronia atual.

Com relação às cartas de Eça de Queiroz a Oliveira Martins, destaca-se a tendência pós-verbal de ordenação dos pronomes adverbiais locativos:

TABELA 5

Ordenação de locativos nas cartas de Eça de Queiroz

\begin{tabular}{l|ccc|ccc}
\hline & \multicolumn{3}{|c|}{ Posições pré- verbais } & \multicolumn{3}{c}{ Posições pós- verbais } \\
\hline Locativo & P1 & P2 & P3 & P4 & P5 & Total \\
\hline Lá & - & 5 & - & 11 & 3 & 19 \\
Ali & - & 1 & - & - & - & 1 \\
Aí & 3 & 7 & 2 & 14 & 4 & 30 \\
Aqui & - & 5 & 3 & 17 & 11 & 36 \\
Cá & - & 3 & 1 & 6 & 2 & 12 \\
Total & 3 & 21 & 6 & 48 & 20 & 98 \\
\hline
\end{tabular}

Como observamos na Tabela 5, dos 98 registros de advérbios locativos, 68 situam-se após o constituinte verbal, principalmente em posição contígua (P4); 
trata-se de ordenação considerada não-marcada dos membros dessa categoria no português contemporâneo. Dos itens em análise, tal como apontado nas tabelas 3 e 4, aqui é o mais frequente, com 36 dados, dos quais 28 ordenam-se após o verbo, como em:

(16) E agora, entro no assunto - que é literatura. Tenho aqui para ti, isto é para o Repórter, dadas certas condições, uma imensa quantidade de prosa. (Carta 12)

(17) Ele veio aqui propor-me uma revista semanal no gênero e tipo da Revue bleue. (Carta 21)

(18) Estou um pouco fatigado, senão contar-te-ia alguns casos engraçados, sobre a nossa Política daqui, a respeito de tratado, imprensa, empréstimo D. Miguel etc. (Carta 31)

Os três fragmentos anteriores são representativos de usos um tanto distintos de aqui. Em (16), trata-se da forma mais regular de sua articulação imediatamente após o verbo, na referência a espaço físico virtual, em que o locativo tem seu sentido um pouco metaforizado, uma vez que o sintagma tenho aqui pode ser interpretado como uma UPF, um tipo de construção mais fixa e integrada, em termos de forma e de função. De acordo com tal entendimento, combinam-se estratégias metafóricas e metonímicas (Traugott e Dasher, 2002), nessa construção.

Com relação a (17), o locativo aqui se insere entre dois constituintes verbais - veio e propor-me, comprometendo aquela que poderia ser, tal como o referido para tenho aqui, uma outra UPF. Ao se pospor a veio, o pronome aqui concorre para a plenitude deste verbo, diminuindo, por outro lado, a possibilidade interpretativa de uma possível locução veio propor-me. Em ordenações como essa, entendemos que o locativo escopa e complementa o verbo antecedente, até mesmo por conta da semântica de movimento de $i r$.

Em (18), o locativo, mais afastado do verbo, perde a conexão maior com este termo e, tal como observado em relação a (12), tende a ser interpretado como tendo como escopo o SN antecedente a nossa Política. Entendemos que nessa nova função temos também uma outra categoria gramatical, que migra de termo adverbial para termo especificador ou clítico, configurando gramaticalização. Por outro lado, interpretamos essa migração como processo, como trajetória ainda 
não concluída, o que permite a consideração de aqui como termo híbrido, à margem de ambas as categorias.

Com 30 registros, o locativo aí é o segundo em frequência na Tabela 5. Com esse termo, Eça de Queiroz faz referência ao espaço do destinatário, Oliveira Martins, geralmente em P4, como em 18 ocorrências, das quais destacamos a seguinte:

(19) ...e se tu, com mais experiência de jornal e de administrações, me quisesses fazer aí uma tabela, enorme favor me farias. (Carta 25)

Quando em ordenações pré-verbais, o aí tende a se metaforizar, numa função anafórica que o situa em posição marginal da classe dos advérbios, tal como:

(20) Munido dessa informação, o requerimento subiu ao Ministério da Fazenda... Mas aí encalhou! (Carta 33)

(21) A ruína dos capitais da gente que lá está, a ruína dos franceses que vivem cá, a baixa no comércio de exportação: eis aí o que seria para a França a bancarrota portuguesa e sem conseguirem a república! (Carta 36)

Em (20), o locativo funciona como segundo membro da UPF mas aí. A sequência verbal articulada com base em subiu (primeiro período) e encalhou (segundo período), concorre para tornar o sentido de aí mais abstrato, passando a competir com outras estruturas alternativas de base temporal, como então, nesse momento, por exemplo. Trata-se, portanto, de efeito de sentido motivado por padrões estruturais, que conduzem à transferência do domínio físico e concreto para o domínio mais abstrato, na referência a tempo.

No fragmento (21), o pronome locativo, na UPF eis aí, retoma todo o trecho antecedente. Assim articulado, o aí passa a assumir traços de conector discursivo, incrementando seu papel textual.

Embora não se possa ignorar totalmente a referência locativa, conforme o princípio da persistência (HOPPER, 1991), o aí em (20) e (21) porta marcas de seu uso no português contemporâneo do Brasil - a tendência pré-verbal, a polissemia e etapas de gramaticalização.

Em (21), encontra-se também o locativo cá, que mantivemos como objeto de pesquisa no século XIX por sua significativa ocorrência, embora não preponderante. Em relação a esse termo, podemos constatar que atua como 
advérbio prototípico: tende a se posicionar após o verbo, escopando-o, na referência a um espaço de granulidade vasta e genérica, próximo ao remetente, que corresponderia ao uso de aqui no português contemporâneo.

\subsection{Século XX}

Os corpora do português contemporâneo são constituídos por textos produzidos exclusivamente no Brasil. Iniciamos a apresentação e análise desta sincronia pelas cartas pessoais de Mário de Andrade a Murilo Miranda. Trata-se de um conjunto de correspondências que se aproxima, em termos de perfil dos interlocutores, das cartas de Eça de Queiroz a Oliveira Martins:

TABELA 6

Ordenação de locativos nas cartas de Mário de Andrade

\begin{tabular}{l|ccc|ccc}
\hline & \multicolumn{3}{|c|}{ Posições pré- verbais } & \multicolumn{3}{c}{ Posições pós- verbais } \\
\hline Locativo & P1 & P2 & P3 & P4 & P5 & Total \\
\hline Lá & - & 5 & - & 4 & 6 & 15 \\
Ali & - & - & 1 & - & 2 & 3 \\
Aí & 2 & 7 & 5 & 29 & 26 & 69 \\
Aqui & 2 & 24 & 5 & 31 & 20 & 82 \\
Total & 4 & 36 & 11 & 64 & 54 & 169 \\
\hline
\end{tabular}

Tal como nas cartas do poeta português do século XIX, na correspondência de Mário de Andrade do século XX revela-se a tendência de ordenação pósverbal dos pronomes adverbiais locativos. A soma de P4 e P5, com 118 dos 169 dados gerais, demonstra o padrão não marcado de uso desses constituintes. Pertence ao advérbio aqui a maior frequência de registros, com 82 ocorrências, entre as quais destacamos:

(22) Tenho tentado trabalhar, que sob este pretexto é que vim aqui, trazendo uma carga de livros e notas. (p. 99)

(23) Nestes primeiros dias paulistanos é certo que posso perceber com facilidade como sou mais eu, como estou em toda minha expansão aqui, como sou feliz. (p. 68) 
(24) Positivamente não posso lhe escrever carta mais derramada neste instante, estou por aqui de ocupações urgentes. (p. 121)

Nos três trechos, o advérbio aqui concorre para a configuração e marcação do espaço do remetente. Seja em P4, como em (22), ou em P5, como em (23), essa ordenação após o verbo caracteriza o uso mais frequente do pronome. Em (24), ocorre a UPF (estou) por aqui, na qual o locativo, num sintagma uno e coeso, além de muito metaforizado, é articulado pelo remetente para expor o excesso de suas ocupações.

O segundo advérbio mais recorrente é aí, que totaliza 69 dados. Desses usos, salienta-se o expressivo número de ordenações pós-verbais - 29 em P4 e 26 em P5. Como justificativa para tal resultado, que, a princípio, contraria a tendência atual de posicionamento pré-verbal de aí, pode-se levantar o argumento de que, na correspondência de Mário de Andrade, esse termo funciona mais efetivamente como advérbio e, portanto, tende a se posicionar após o verbo, assumindo assim um dos traços prototípicos da classe adverbial. Consideramos que esse alto índice de ocorrência e o tipo de função de aí são motivados pragmaticamente, uma vez que o remetente dirige-se muito a seu interlocutor, por intermédio de perguntas, pedidos, questionamentos, entre outros; essas estratégias interlocutivas ensejam também a referência ao espaço do outro, ao aí, tal como:

(25) Você por acaso não leu aí, creio que na Folha Carioca, ou no outro jornal Carioca no título, uma nota do Joaquim Cardozo, sobre Macunaíma? (p. 181)

(26) Acabei sempre sabendo que está preparando por aí alguma coisa que não sei bem ao certo inteiramente o que é nem como é. (p. 145)

O levantamento da ordenação e da função do locativo aína correspondência de Mário de Andrade evidencia a necessidade de que a abordagem do fato gramatical seja feita com base no nível do texto ou do discurso. Se nos detivermos apenas no fenômeno linguístico stricto sensu, perdemos a chance e a oportunidade de levantarmos motivações maiores, que podem nos apontar alternativas muito interessantes para a interpretação do que ocorre no âmbito da frase ou da oração.

Podemos também dizer isso em relação aos usos de ali. No sentido contrário, com baixa frequência, encontra-se esse locativo, que apenas registra três ocorrências entre as 169 gerais. Consideramos que a ausência de sequências 
tipológicas narrativas é um traço discursivo relevante para essa quase nula ocorrência. As cartas de Mário são organizadas basicamente por trechos expositivos e injuntivos; os relatos são esporádicos, portanto, como locativo típico de narrativas, o elemento ali fica praticamente ausente nessas cartas. Nas três ocasiões em que ali é usado por Mário de Andrade, sua referência encontra-se metaforizada e o sentido temporal prevalece, como nos dois trechos a seguir:

(27) Temo não estar certo. Venho de tais discussões e dúvidas, estas discussões, dúvidas, sofrimentos que assaltam a gente na noite, ali na piririca, nítidos, visíveis, tangíveis... (p. 130)

(28) Manuela é a minha Ramington, comprada nem sei mais quando ali por 1920 e que até agora está perfeitíssima. (p. 150)

Nos fragmentos expositivos (27) e (28), os termos noite e quando, respectivamente, prenunciam, por anáfora, o sentido mais temporal de ali, que, na sequência, é preenchido cataforicamente pelos sintagmas na piririca e por 1920. Trata-se de uma situação discursiva que contrasta, por exemplo, com a Carta de Caminha, em que a grande profusão de relatos concorre para o aumento da frequência de aqui, em sentido físico concreto.

Nas cartas de Mário de Andrade, verificamos usos polissêmicos e mais gramaticalizados em torno do locativo lá:

(29) ... nestas 15 horas de sol maravilhoso entrava na cama, ficava quietinho, não existia, acabava dormindo, me acordava lá pelas altas horas, me vestia, ia comer um bife com vinho forte na cidade. (p. 169)

(30) Vá lá, publique as minhas cartas à Cecília, si quiser. (p. 173)

Em (29), a referência do locativo é temporal; inserido numa construção em torno do verbo acordar e seguido pelo sintagma pelas altas horas, o pronome lá assume sentido temporal, numa referência vaga e imprecisa, coerente com o tom informal de todo o fragmento. Já em (30) a polissemia do locativo é maior ainda; como componente da UPF vá lá, o termo encontra-se altamente abstratizado, servindo mais a propósitos pragmáticos do que informacionais; trata-se de uma construção de caráter modalizador, praticamente fora do âmbito sintático oracional. 
No segundo conjunto de textos pesquisados no século XX, confirmamos os contextos informais, organizados em torno de usos mais coloquiais, como favorecedores da polissemia e gramaticalização dos locativos:

TABELA 7

Ordenação de locativos nas cartas de leitores

\begin{tabular}{l|ccc|ccc}
\hline & \multicolumn{3}{|c|}{ Posições pré- verbais } & \multicolumn{3}{c}{ Posições pós- verbais } \\
\hline Locativo & P1 & P2 & P3 & P4 & P5 & Total \\
\hline Lá & 3 & 4 & 4 & 16 & 2 & 29 \\
Ali & - & 6 & 1 & 2 & 2 & 11 \\
Aí & 1 & 9 & 6 & 11 & 3 & 30 \\
Aqui & 2 & 2 & 6 & 10 & 8 & 28 \\
Total & 6 & 21 & 17 & 39 & 15 & 98 \\
\hline
\end{tabular}

Os 98 dados apresentados na Tabela 7 trazem resultados um tanto distintos, comparados aos da Tabela 6, do mesmo século XX, e aos das tabelas anteriores, de sincronias passadas. A maior frequência de locativos registrada é de aí, com 30 dados, seguida de lá e aqui, com 29 e 28 dados, respectivamente.

Consideramos que esses índices têm a ver com o subgênero em elaboração e as sequências tipológicas em que é organizado. Na tabela que se segue, apresentamos a distribuição dos 98 dados de acordo com esse fator:

TABELA 8

Sequência tipológica em que se insere o locativo nas cartas dos leitores

\begin{tabular}{l|ccc|ccc}
\hline & \multicolumn{3}{|c|}{ Posições pré- verbais } & \multicolumn{3}{c}{ Posições pós- verbais } \\
\hline Locativo & P1 & P2 & P3 & P4 & P5 & Total \\
\hline Lá & 7 & 2 & 11 & 9 & 0 & 29 \\
Ali & 4 & 0 & 5 & 2 & 0 & 11 \\
Aí & 1 & 2 & 19 & 5 & 3 & 30 \\
Aqui & 10 & 1 & 10 & 5 & 2 & 28 \\
Total & 23 & 6 & 46 & 21 & 5 & 98 \\
\hline
\end{tabular}

Como podemos observar, praticamente a metade dos dados articula sequências expositivas. Nas cartas de leitores, esses trechos são usados para a expressão de opinião ou ponto de vista, em geral acerca de assunto polêmico. 
Embora o texto seja elaborado na modalidade escrita e o veículo pertença à chamada mídia de prestígio, não raramente os leitores utilizam construções mais coloquiais nesses comentários. Tal situação concorre para a articulação mais frequente de aí e lá em referência polissêmica ou em processo de gramaticalização. Em relação ao primeiro locativo, temos, por exemplo, usos como:

(31) Agora dizem que não há dinheiro, e que o salário mínimo é "mínimo" porque, do contrário, não haveria como pagar aos aposentados. E aí vem o ministro José Dirceu pregando a desvinculação, ou seja, para aumentar decentemente o mínimo, temos que matar de fome os aposentados, roubando-lhes o dinheiro que eles e seus empregadores.. (JB on line, 05/05/04)

(32) Cabe a questão: Lula acredita no que prega? Se sim, o nosso presidente padece de algum mal que simplesmente o leva a dissociar sua retórica das suas ações. Se não, bem, aí a gravidade é óbvia. (Folha de São Paulo, 10/05/04)

(33) Agora, às vésperas das eleições, ela e sua equipe estão tentando mostrar algum serviço, mas aí aparece a incompetência. (Folha de São Paulo, 10/04/04)

Nesses trechos, os leitores expõem seu ponto de vista, na elaboração de fragmentos opinativos marcados pelo maior nível de abstratização do sentido como um todo. Inserido em tais sequências, o elemento aí passa a partilhar também essa referência polissêmica, funcionando como uma das estratégias linguísticas para tal fim. Nos três fragmentos acima, o locativo aí, em posição pré-verbal e referência anafórica, atua também como elemento de conexão. Nessa função, pode combinar-se com outros constituintes na formação de UPF, do tipo e aí (31) ou mas aí (33). Assim articulado, perde traços da classe adverbial e começa a migrar para a categoria conectiva, configurando etapa de gramaticalização. Dos 30 registros de aí levantados nesse corpus, em 16 encontramos o locativo na ordenação e função correspondentes aos três segmentos apresentados; em nenhum dos demais corpora obtivemos resultado semelhante.

Em relação a lá, o segundo mais frequente dos locativos, também verificamos sentidos polissêmicos, distantes da referência física concreta e em migração categorial: 
(34) Portanto, tentar classificar ato como esse como político, ou seja lá o que se disser sobre a insanidade, só demonstra toda nossa incompreensão. (IstoÉ, 24/03/04)

(35) Toda semana, sem exageros, outras vias principais são fechadas entre conflito com a polícia e traficante. Mas deixa para lá, é no subúrbio. (O Globo, 18/04/04)

(36) ISTO É foi a única revista que tocou nessa questão tão delicada que é a entrega cínica das nossas riquezas para um sem-número de ONGs a serviço sabe-se lá de quem. (IstoÉ, 24/03/04)

Os três fragmentos ilustram a tendência de ordenação pós-verbal de lá e seu uso mais abstratizado, na formação das UPF seja lá, deixa para lá e sabe-se lá. Como constituintes finais dessas construções, o locativo lá, tal como os demais componentes de tais estruturas, encontra-se altamente abstratizado. A granulidade vasta que caracteriza lá faz desse locativo elemento estratégico na articulação da referência genérica e imprecisa. Seu uso nos trechos citados confere aos depoimentos dos leitores a marca da vaguidão e por vezes mesmo da negação.

Em relação a aqui, o terceiro mais frequente locativo, podemos dizer que tem efetivamente uso adverbial. Tal como nas demais cartas pesquisadas no século XX e nas demais sincronias, a função de aqui é a de delimitar e referir o espaço do remetente. Embora apresente variabilidade em sua ordenação, tende a ocorrer no século XX em posição pós-verbal e referência mais concreta, em conformidade com a tendência dos prototípicos advérbios:

(37) Estou de férias no Chile. Contudo, li com muita preocupação no Globo a situação da Rocinha. A notícia repercutiu mal aqui e muitos me perguntaram por que o Rio chegou a tal ponto. (Veja, 28/04/04)

(38) Gostaria de saber por que os governantes do Rio tratam com tanto descaso o bairro da Glória. Moro aqui há 21 anos, desde que nasci, e há muitos os mendigos, inúmeros os pontos de mototáxi nas ruas do bairro. (O Globo, 24/05/04) 


\section{Considerações finais}

O levantamento exaustivo e a análise dos pronomes adverbiais locativos em textos de cartas elaboradas em três períodos do português, do ponto de vista estritamente gramatical, apontam-nos variabilidade e tendências de mudança. Observamos que, ao longo da trajetória da língua, esses elementos ordenam-se variadamente no interior da oração, podendo situar-se ante ou após o verbo, admitindo ou não inserções em relação ao constituinte verbal. Trata-se de fenômeno verificado em todas as sincronias.

No entanto, essa variabilidade posicional dos locativos tende a diminuir, a partir do século XIX, pelo menos para os prototípicos usos adverbiais. Tal diminuição se dá por conta da maior frequência da posição pós-verbal, que interpretamos como ordenação não marcada no português contemporâneo.

Do ponto de vista discursivo, o uso mais frequente de aqui na maioria das fases pesquisadas, conforme verificamos nas tabelas $3,4,5$ e 6 , nos permite dizer que se trata do mais regular e frequente modo de referência espacial no gênero epistolar, a forma não marcada de articulação do pronome adverbial locativo nesse contexto discursivo. Quando outras motivações entram em jogo, específicas de determinados ambientes interacionais, como a Carta de Caminha ou as cartas de leitores, essa tendência pode se alterar, com o maior uso de outros membros da categoria, como ali e aí, respectivamente.

Em relação às cartas de leitores do século XX, encontramos dados que, pelo menos teoricamente, referem-se a usos mais polissêmicos e recentes dos locativos aí e lá. Tais usos admitem situar esses dois elementos em posição marginal na classe dos advérbios. Nos textos das fases anteriores, não registramos essa frequência e mesmo a maior parte desses usos. Por outro lado, os demais textos pertencem a outro subgênero discursivo (carta pessoal, carta oficial) e envolvem interlocutores distintos (familiares, amigos intelectuais, autoridades), com propósitos comunicativos diversos. Esses fatores não nos possibilitam, portanto, considerar que as ocorrências de aí e de lá nas cartas de leitores sejam motivadas exclusivamente por fator de natureza cronológica, relativo à unidirecionalidade.

O que a análise até aqui nos permite declarar é que, para a interpretação da ordenação e da função dos pronomes locativos no gênero epistolar, é necessária a compatibilização da abordagem gramatical e da discursivopragmática. As duas dimensões são complementares no tratamento dos fenômenos que investigamos. 
Assim, instâncias como gênero e subgênero discursivo, tipo de sequência tipológica, propósitos comunicativos e perfil dos interlocutores motivam a seleção e uso dos recursos gramaticais. É exatamente essa vinculação que temos observado na pesquisa dos pronomes adverbiais locativos e que deve também ser incorporada na abordagem histórica dessas manifestações.

\section{Notas}

${ }^{1}$ Trabalharam no levantamento, descrição e análise preliminar dos dados em texto epistolar os bolsistas IC Luciana Pomponet Cardozo da Silva (Faperj), na pesquisa do português arcaico e contemporâneo, e Thiago Quintas Valadares (Unibanco), na pesquisa do português dos séculos XVIII e XIX.

${ }^{2}$ Edição da Comissão Executiva das Comemorações do V Centenário do Nascimento de Pedro Álvares Cabral. Lisboa: 1968. Texto transcrito do L. 13 da Reforma dos Documentos das Gavetas a f. 43.

${ }^{3}$ Usamos os corpora eletrônicos dos sites: www.letras.ufrj.br/phpb-rj e http://www.ime.usp.br/ tycho.

\section{Referências}

BARBOSA, A. Normas cultas e normas vernáculas: a encruzilhada histórico-diacrônica nos estudos sobre português brasileiro. In: CASTILHO, A. et al. (Org.). Descrição, história e aquisição do português brasileiro. São Paulo: Pontes/Fapesp, 2007. p 483-498.

BATORÉO, H. Expressão do espaço no português europeu: contributo psicolinguístico para o estudo da linguagem e cognição. Coimbra: Fundação Calouste Gulbenkian, 2000. 930p.

BERLINCK, R. A; BARBOSA, J. B; MARINE, T.C. Reflexões teórico-metodológicas sobre fontes para o estudo histórico da língua. Revista da ABRALIN, v. 7, n. 2, p. 169-196, 2008.

BONINI, A. A noção de sequência textual na análise pragmático-textual de JeanMichel Adam. In: MEURER, J. L; BONINI, A.; MOTTA-ROTH, D. (Org.). Gêneros: teorias, métodos, debates. São Paulo: Parábola, 2005. p. 208-236.

BRAGA, M. L.; PAIVA, M. Do advérbio ao clítico é isso aí. In: RONCARATI, C.; ABRAÇADO, J. (Org.). Português brasileiro - contato linguístico, heterogeneidade e história. Rio de Janeiro: 7Letras, 2003. p. 206-212. 
BRINTON, L; TRAUGOTT, E. Lexicalization and language change. Cambridge: Cambridge University Press, 2006. 207p.

ERMAN, B; WARREN, B. The idiom principle and the open choice principle. Linguistic - an interdisciplinary journal of the language sciences. Berlin/New York: Mouton de Gruyter, n. 2, 2000. p. 29-62.

FISCHER, O; NORDE, M; PERRIDON, H. (Ed.). Up and down the cline - the nature of grammaticalization. Amsterdam/Philadelphia: John Benjamins, 2004. 404p.

FONTANINI, I. Cartas ao editor: a linguagem como forma de identificação social e ideológica. In: MEURER, J. L.; MOTTA-ROTH, D. (Org.). Gêneros textuais e práticas discursivas. Bauru: EDUSC, 2002. p. 225-238.

GOLDBERG, A. Constructions at work - The nature of generalization in language. Oxford: Oxford University Presss, 2006. 280p.

GOLDBERG, A. Constructions: A construction grammar approach to argument structure. Chicago/London: The University of Chicago Press, 1995. 265p.

HEINE, B.; KUTEVA, T. Language contact na grammatical change. Cambridge: Cambridge University Press, 2005. 308p.

HOPPER, P. On some principles of grammaticization. In: TRAUGOTT E.; HEINE, B (Ed.) Approaches to grammaticalization. Vol I. Focus on theoretical and methodological issues, Amsterdam: John Benjamins, 1991. p 17-36.

MARCUSCHI, L. A. Gêneros textuais: definição e funcionalidade. In: DIONÍSIO, A.; MACHADO, A.; BEZERRA, M. A. (Org.). Gêneros textuais \& ensino. Rio de Janeiro: Lucerna, 2002. p. 19-36.

MATTOS E SILVA, R. V. O português arcaico: fonologia. São Paulo/Bahia: Contexto / Editora Universidade Federal da Bahia, 1991. 101p.

OLIVEIRA, M. R. Ordenação de advérbios locativos no português escrito - uma abordagem histórica. Relatório final de pesquisa apresentado ao CNPq. Rio de Janeiro, 2007. 50p.

OLIVEIRA, M. R.; AGUIAR, M. T. A trajetória de gramaticalização advérbio > clítico no uso do pronomes aí, ali, aqui e lá. IN: OLIVEIRA, M. R.; ROSÁRIO, I. C. (Org.). Pesquisa em linguística funcional: convergências e divergências. Rio de Janeiro: Léo Christiano Editorial, 2009. p. 142-152.

TARALLO, F. Tempos linguísticos: itinerário histórico da língua portuguesa. São Paulo: Ática, 1990. 208p. 
TAVARES, M. A. Metáfora e metonímia em processos de gramaticalização: o caso de "aî" marcador de especificação. Revista Gragoatá, n. 27. Niterói: Eduff (no prelo).

TAYLOR, J. Linguistic categorization: prototypes in linguistic theory. Oxford: Clarendon Press, 1995. 270p.

TRAUGOTT, E.; DASHER, R. Regularity in semantic change. Cambridge: Cambridge University Press, 2005. 341p. 